\title{
Carbon Nanofibers Modified Graphite Felt for High Performance Anode in High Substrate Concentration Microbial Fuel Cells
}

\author{
Youliang Shen, ${ }^{1,2}$ Yan Zhou, ${ }^{3}$ Shuiliang Chen, ${ }^{3}$ \\ Fangfang Yang, ${ }^{3}$ Suqi Zheng, ${ }^{3}$ and Haoqing Hou ${ }^{1,3}$ \\ ${ }^{1}$ School of Materials Science and Engineering, Nanchang University, Nanchang 330031, China \\ ${ }^{2}$ Jiangxi Key Laboratory of Surface Engineering, Jiangxi Science \& Technology Normal University, Nanchang 330013, China \\ ${ }^{3}$ Department of Chemistry and Chemical Engineering, Jiangxi Normal University, Nanchang 330022, China
}

Correspondence should be addressed to Shuiliang Chen; slchenjxnu@jxnu.edu.cn and Haoqing Hou; haoqing@jxnu.edu.cn

Received 25 December 2013; Accepted 19 February 2014; Published 22 April 2014

Academic Editors: B. Cao, H.-C. Tao, and Y.-C. Yong

Copyright (C) 2014 Youliang Shen et al. This is an open access article distributed under the Creative Commons Attribution License, which permits unrestricted use, distribution, and reproduction in any medium, provided the original work is properly cited.

\begin{abstract}
Carbon nanofibers modified graphite fibers (CNFs/GF) composite electrode was prepared for anode in high substrate concentration microbial fuel cells. Electrochemical tests showed that the CNFs/GF anode generated a peak current density of $2.42 \mathrm{~mA} \mathrm{~cm}$ at a low acetate concentration of $20 \mathrm{mM}$, which was $54 \%$ higher than that from bare GF. Increase of the acetate concentration to $80 \mathrm{mM}$, in which the peak current density of the CNFs/GF anode greatly increased and was up to $3.57 \mathrm{~mA} \mathrm{~cm}^{-2}$, was seven times as that of GF anode. Morphology characterization revealed that the biofilms in the CNFs/GF anode were much denser than those in the bare GF. This result revealed that the nanostructure in the anode not only enhanced current generation but also could tolerate high substrate concentration.
\end{abstract}

\section{Introduction}

Microbial fuel cells (MFCs) are electrochemical devices that use electroactive microorganisms to oxidize organic chemicals and generate electric power [1]. Based on the "green" power source characteristic, the MFCs show great potential in many applications including wastewater treatment, biosensors, water desalination, remote power sources, biohydrogen production, and heavy metal removal and recovery [2-4]. Currently, the limited performance is one of main obstacles for the MFC on the way to practical application.

Anode related to the biofilm growth plays a crucial role on the performance of MFCs. Recently, some measures have been taken to improve the performance of anode, which mainly included architecture design and surface modification. Various macroporous carbons were developed for anodes in MFCs, such as carbon papers [5], carbon cloth [6], graphite rod [7], graphite fiber brush [8], reticulated vitrified carbon (RVC) [7], graphite felt [9], electrospun carbon fiber mats [10], natural plant derived carbon materials [11], and layered corrugated carbon [12]. Simultaneously, some composite materials prepared by surface modification were also studied as high performance anodes in MFCs, such as redox or conducting polymer [13-15] and nanocarbons [16], modified carbon materials $[17,18]$, and carbon nanotubecoated macroporous polymers $[19,20]$.

Though the highest anodic current density of $400 \mathrm{~A} \mathrm{~m}^{-2}$ was obtained in one of our previous studies by using layered corrugated carbon [12], the performance of these anodes was measured under relatively low-concentration substrate, for example, below $20 \mathrm{mM}$ acetate. Though a diversity of substrates were employed as substrates in MFCs, including saccharides, alcohols, and different kinds of wastewater, which had been summarized in some review such as [21], the study on the performance of anode in MFCs under high concentration substrate was rare. The tolerance of high 


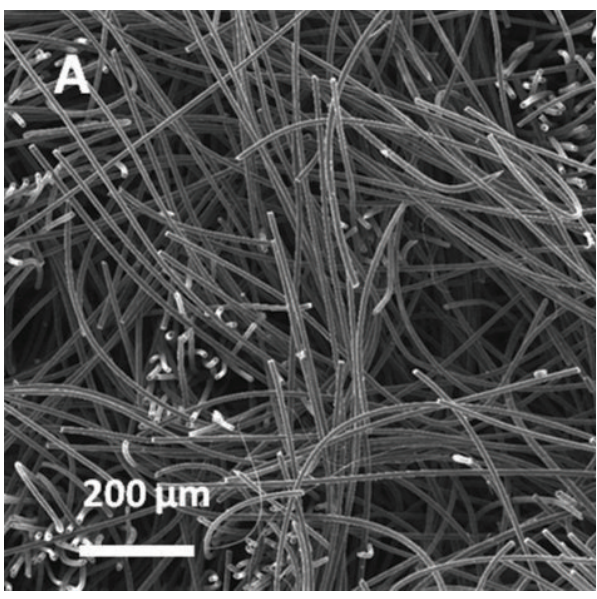

(a)

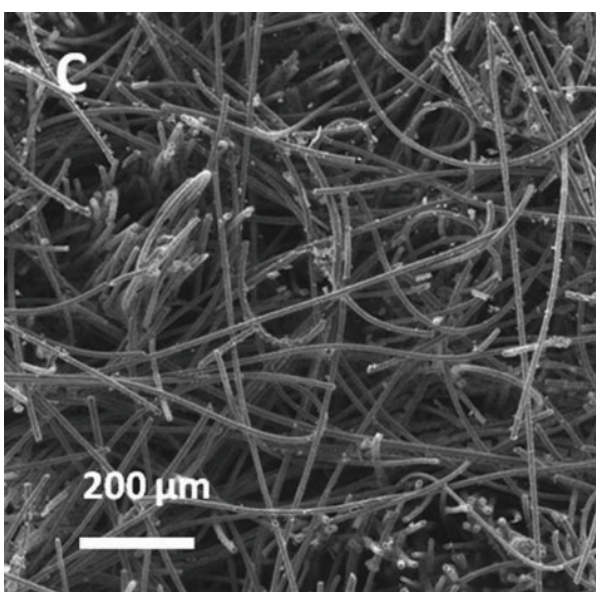

(c)

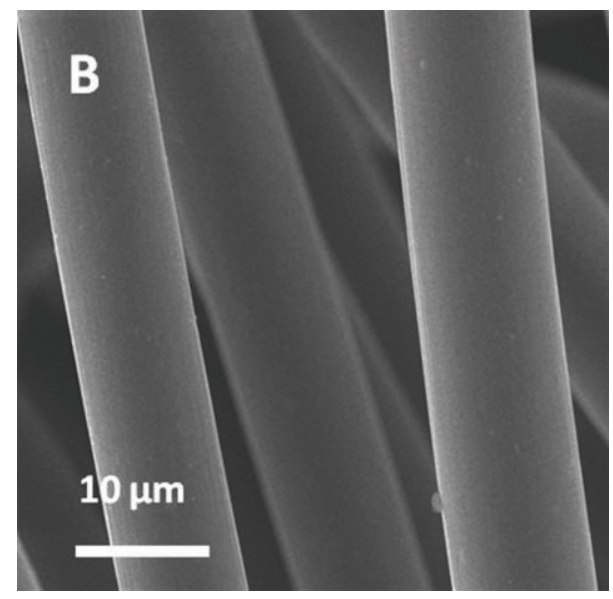

(b)

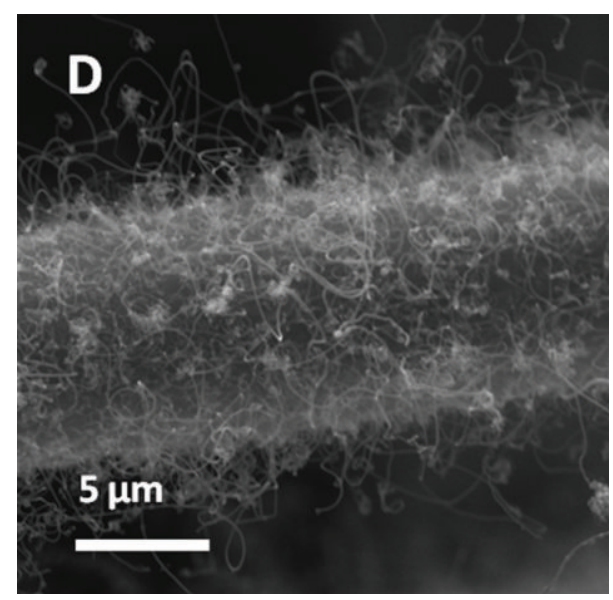

(d)

Figure 1: SEM images of ((a) and (b)) GF and ((c) and (d)) CNFs/GF.

concentration substrate would expand the application of MFCs to treat high strength wastewater, thus showing great help for practical application.

In this study, we report carbon nanofiber modified graphite felt (CNFs/GF) for anode in high substrate concentration microbial fuel cells. CNFs/GF anode is prepared by growth of CNFs on GF via chemical vapor deposition. The anodic performance of the CNFs/GF anode in different concentration of acetate is investigated, as well as the behavior of biofilms in the CNFs/GF, and compared with the bare graphite felt.

\section{Method}

2.1. Materials Preparation and Characterization. Graphite felt (GF) (Hunan Jiuhua Carbon High-Tech Co., Xiangtan, Hunan, China) was firstly soaked in $10 \mathrm{wt} \% \mathrm{FeCl}_{3}$ for $1 \mathrm{~h}$ and then dried in a vacuum oven at $100^{\circ} \mathrm{C}$ for $1 \mathrm{~h}$. The growth of carbon nanofibers onto GF was conducted in a furnace equipped with a quartz tube. The GF was heated to $850^{\circ} \mathrm{C}$ at a rate of $5^{\circ} \mathrm{C} / \mathrm{min}$ in $\mathrm{N}_{2}$ atmosphere, then inlet the mixture of $\mathrm{H}_{2}$ and $\mathrm{N}_{2}\left(\mathrm{H}_{2} / \mathrm{N}_{2}=1: 4\right)$ at a total flow of $100 \mathrm{~mL} \mathrm{~min}^{-1}$ for $1 \mathrm{~h}$ to reduce the Fe (III) to Fe (0). Subsequently, let the furnace cool down to about $750^{\circ} \mathrm{C}$ and then inlet acetylene with rate of $10 \mathrm{~mL} \mathrm{~min}^{-1}$ for $5 \mathrm{~min}$. After cooling down to room temperature naturally, the $\mathrm{CNF} / \mathrm{GF}$ was taken out. The residue $\mathrm{Fe}$ in the $\mathrm{CNF} / \mathrm{GF}$ was removed by socking it in $0.5 \mathrm{M}$ hydrochloric acid solution and rinsed with distilled water. At last, the samples were dried in the drying oven at $100^{\circ} \mathrm{C}$ for $1 \mathrm{~h}$. The morphology characterization of samples was observed by a Tescan Vega-3 scanning electron microscope (SEM).

2.2. Electrode Preparation. Graphite plate (GP) cut into pieces with size of $1 \times 1 \mathrm{~cm}^{2}$ was connected with stainless wire and encapsulated by epoxy resin. One side of GP was polished by 2000 mesh sandpaper and used as support for anode electrode. The CNFs/GF and GF were cut into pieces with the same size as the GP and glued onto the polished GP by conductive glue.

2.3. Electrochemical Measurement. Primary domestic wastewater was collected from the wastewater treatment plant (Qingshan, Nanchang, China) and used as the inoculum to 
select secondary biofilms through procedures following previous report [11]. All current density data in this paper refer to secondary biofilms and the electrochemical performance tests were conducted when the biofilms activity reached stationary level.

The electrochemical measurements were carried out in three-electrode half-cell, in which a $500 \mathrm{~mL}$ bottle was assembled with six working electrodes, one $\mathrm{Ag} / \mathrm{AgCl}$ reference electrode (saturated $\mathrm{KCl}, 0.198 \mathrm{~V}$ versus standard hydrogen electrode (SHE)) and one carbon felt counter electrode $\left(8 \mathrm{~cm}^{2}\right)$. The experiments were carried out with computer controlled potentiostat (CHI1040B) which was equipped with eight channels in parallel. For the chronoamperometric (CA) measurement, a potential of $+0.2 \mathrm{~V}$ was applied onto the working electrodes and the current was recorded. All experimental operations were conducted anaerobically at $35^{\circ} \mathrm{C}$ which was the optimal growth temperature of bacteriain $50 \mathrm{mM}$ phosphate buffer solution $(\mathrm{pH}=7.0)$ with different concentrations of acetate substrate. All of the electrode potentials were given as versus $\mathrm{Ag} / \mathrm{AgCl}$ and all of the current density values were normalized to the projected surface area.

2.4. Biofilm SEM Imaging. The morphology of the biofilm was characterized by scanning electron microscopy (SEM). The biofilm samples for SEM characterization were prepared as follows [11], biofilm samples were firstly fixed by $5 \mathrm{wt} \%$ glutaric aldehydes in $50 \mathrm{mM}$ phosphate buffer solution $(\mathrm{pH}$ $=7.0$ ), then dehydrated in a graded series of ethanol aqueous solution $(10 \%, 25 \%, 40 \%, 55 \%, 70 \%, 80 \%, 90 \%$, and $100 \%)$, and finally dried naturally at room temperature. After coating a layer of gold, the biofilm samples were observed under SEM.

\section{Results and Discussion}

3.1. Morphologies of GF and CNFs/GF. Figure 1 shows the SEM images of GF and CNFs. The diameter of graphite fiber in the GF is about $10 \mu \mathrm{m}$. The GF has a macroporous structure with pore size in the tens of micrometers. Detailed SEM image in Figure 1(b) shows that the surface of GF is smooth. After a CVD process, a layer of long length carbon nanofibers with diameter of about $100 \mathrm{~nm}$ was successfully grown onto the graphite fibers surface to form CNFs/GF composite (Figure 1(d)), which is in accordance with the micro/nano structures of carbon composite in [22]. The CNFs/GF displays a hierarchical micro-/nanostructures which would be beneficial for the attachment of bacteria to the anode and enhancement of electron transfer from inside bacteria to the anode simultaneously.

3.2. Biocatalytic Current Generation of $G F$ and $C N F s / G F$ Anode. The biocatalytic current generation curves of GF and $\mathrm{CNFs} / \mathrm{GF}$ anodes under different concentration of acetate are shown in Figure 2. It can be observed that the CNFs/GF anode achieves the maximum current density at the second cycle, while the GF requires three cycles. This result demonstrates the CNFs modification enhances the attachment of the bacteria to the anode. After running for six cycles under low acetate concentration of $20 \mathrm{mM}$, the GF and CNFs/GF anodes

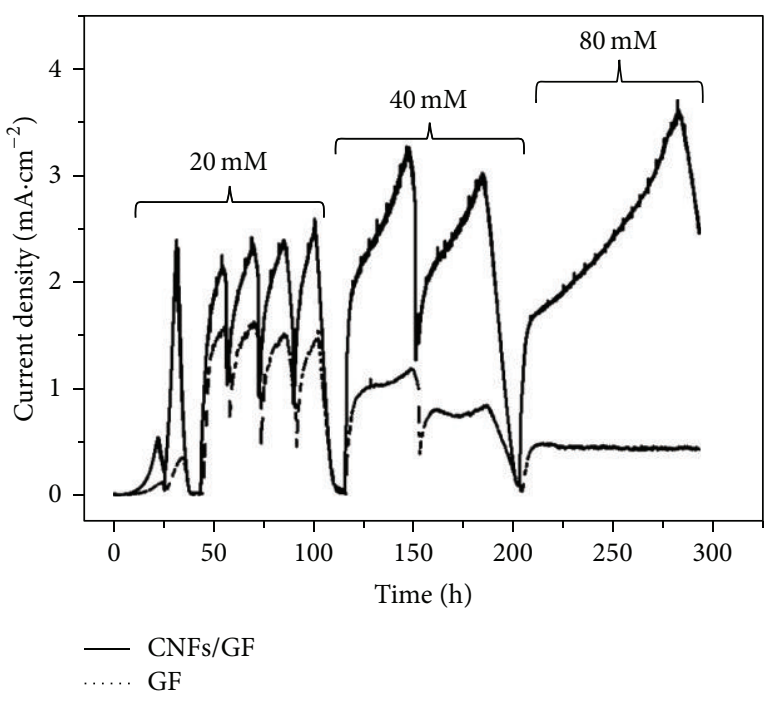

FIGURE 2: Biocatalytic current generation curves of GF (curves of dotted line) and CNFs/GF (curves of solid line) under different concentration of acetate measured in a half cell at $35^{\circ} \mathrm{C}$. The arrows indicate the replenishment of the substrate with different concentration of acetate.

all delivered a stable maximum current density. The CNFs/GF anode generates a maximum geometric current density of about $2.42 \mathrm{~mA} \mathrm{~cm}^{-2}$, which is $54 \%$ higher than that from GF of about $1.57 \mathrm{~mA} \mathrm{~cm}^{-2}$. By increasing the concentration of acetate to $40 \mathrm{mM}$, the current density of GF anode shows a slight decrease to $1.17 \mathrm{~mA} \mathrm{~cm}^{-2}$, while the CNFs/GF anode produces a much higher current density of $3.23 \mathrm{~mA} \mathrm{~cm}^{-2}$, about $33 \%$ higher than that under $20 \mathrm{mM}$ acetate. By further increasing the concentration of acetate to $80 \mathrm{mM}$, the maximum current density of the CNFs/GF anode keeps increasing to about $3.57 \mathrm{~mA} \mathrm{~cm}^{-2}$, in contrast, that of the bare GF anode greatly decreases to only about $0.50 \mathrm{~mA} \mathrm{~cm}^{-2}$. It could be concluded that the CNFs/GF anode shows excellent performance of tolerating high strength substrate and that excellent performance is brought by the CNFs modification. It was reported that nanocarbons modification could enhance the attachment of the biofilm and the electron transfer from inside bacteria to the surface of anode and thus increased and stabled the anodic current generation [16-18, 22]. In this paper, the CNFs modification not only increases the current generation, but also shows high performance of tolerating high strength substrate. That could also be attributed to the enhancement of electron transfer (respiration) by the CNFs modification and acceleration of the metabolism of the biofilms in the anode.

3.3. Morphology of Biofilms on GF and CNFs/GF. In order to verify the anodic performance, after current generation in media with $80 \mathrm{mM}$ acetate, the GF and CNFs/GF anodes with biofilms are taken out. After fixation and drying, the biofilms in the GF and CNFs/GF are observed under the SEM. Figure 3 shows the images of biofilms grown in the GF and CNFs/GF. It can be seen from the overview images 


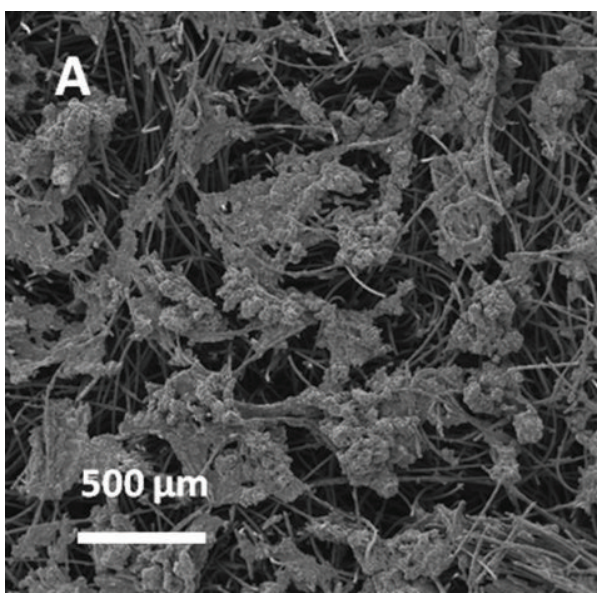

(a)

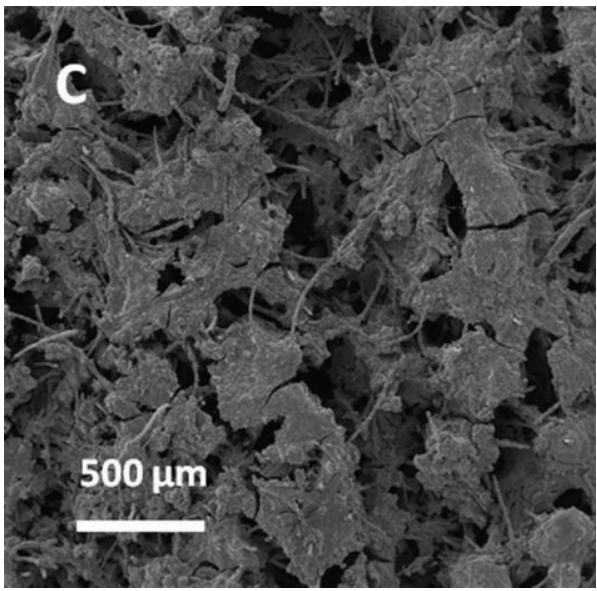

(c)

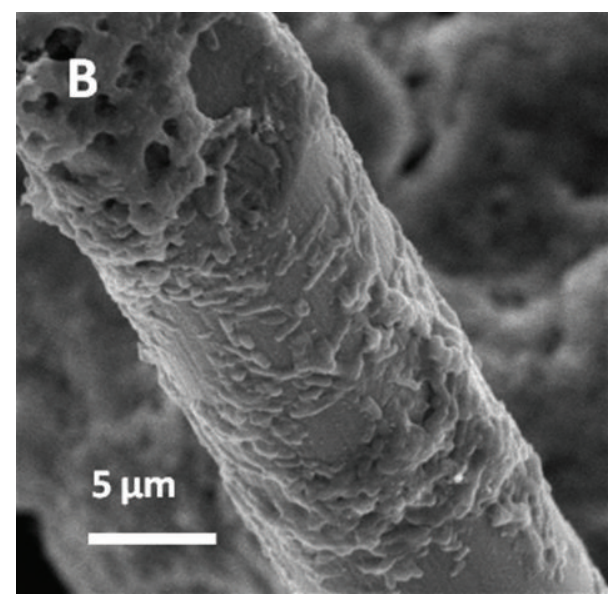

(b)

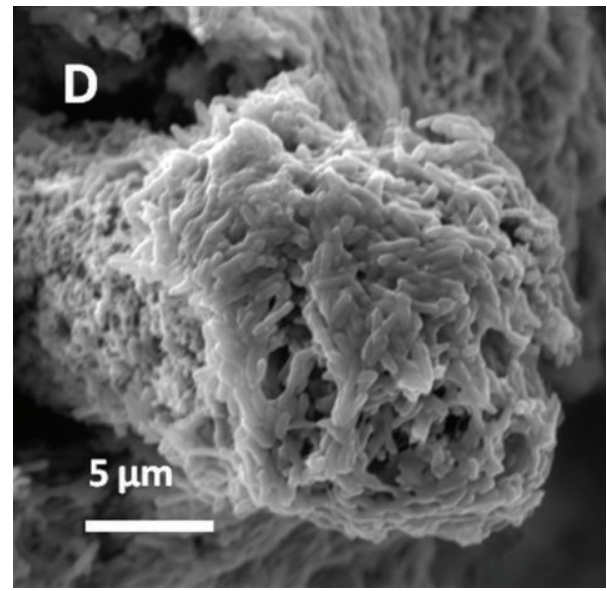

(d)

Figure 3: Overview and detailed SEM images of ((a) and (b)) biofilms in GF and ((c) and (d)) CNFs/GF.

(Figures 3(a) and 3(c)) that the biofilms grown in the $\mathrm{CNF} / \mathrm{GF}$ anode are denser than those in the GF anode. Detailed observation of biofilms on individual fiber (Figures 3 (b) and $3(\mathrm{~d})$ ) reveals that the biofilms on bare graphite fibers are sparse, while those on the CNFs modified fibers are very thick and have a thickness of about $5 \mu \mathrm{m}$ on individual graphite fiber according to the SEM image in Figure 3(d). That confirms that the current generation for the CNFs/GF is higher than that of the bare GF.

\section{Conclusion}

The performance of tolerating high strength substrate for the CNFs modified GF was demonstrated. The CNFs/GF not only generate enhanced current density in low strength acetate media of $20 \mathrm{mM}$ comparing to the bare GF but also could generate a much higher current density of $3.57 \mathrm{~mA} \mathrm{~cm}^{-2}$ in high strength acetate media of $80 \mathrm{mM}$, which was 7 times higher than that generated from bare GF. The performance of tolerating high strength substrate was attributed to the nanostructured CNFs which enhanced the electron transfer from inside bacteria to anode (respiration) and accelerated the metabolism of bacteria. Anode materials tolerating high strength substrate would expand the applications of MFCs in high concentration of substrate environment, for example, high strength wastewater treatment from oil and food industry.

\section{Conflict of Interests}

The authors declare that there is no conflict of interests regarding the publication of this paper.

\section{Acknowledgments}

This research was supported by the National Natural Science Foundation of China (Grant no. 51202096) and the Science and Technology Project of Jiangxi Province (no. 20121BBE50024).

\section{References}

[1] K. Rabaey and W. Verstraete, "Microbial fuel cells: novel biotechnology for energy generation," Trends in Biotechnology, vol. 23, no. 6, pp. 291-298, 2005. 
[2] F. Harnisch and U. Schröder, "From MFC to MXC: chemical and biological cathodes and their potential for microbial bioelectrochemical systems," Chemical Society Reviews, vol. 39, no. 11, pp. 4433-4448, 2010.

[3] Y. Qiao, S. J. Bao, and C. M. Li, "Electrocatalysis in microbial fuel cells-from electrode material to direct electrochemistry," Energy \& Environmental Science, vol. 3, no. 5, pp. 544-553, 2010.

[4] K. R. Fradler, I. Michie, R. M. Dinsdale, A. J. Guwy, and G. C. Premier, "Augmenting microbial fuel cell power by coupling with supported liquid membrane permeation for zinc recovery," Water Research, vol. 55, pp. 115-125, 2014.

[5] B. Min and B. E. Logan, "Continuous electricity generation from domestic wastewater and organic substrates in a flat plate microbial fuel cell," Environmental Science \& Technology, vol. 38, no. 21, pp. 5809-5814, 2004.

[6] S. Cheng, H. Liu, and B. E. Logan, "Increased power generation in a continuous flow MFC with advective flow through the porous anode and reduced electrode spacing," Environmental Science \& Technology, vol. 40, no. 7, pp. 2426-2432, 2006.

[7] Z. He, S. D. Minteer, and L. T. Angenent, "Electricity generation from artificial wastewater using an upflow microbial fuel cell," Environmental Science \& Technology, vol. 39, no. 14, pp. 52625267, 2005.

[8] B. Logan, S. Cheng, V. Watson, and G. Estadt, "Graphite fiber brush anodes for increased power production in air-cathode microbial fuel cells," Environmental Science \& Technology, vol. 41, no. 9, pp. 3341-3346, 2007.

[9] Y. Liu, F. Harnisch, K. Fricke, U. Schröder, V. Climent, and J. M. Feliu, "The study of electrochemically active microbial biofilms on different carbon-based anode materials in microbial fuel cells," Biosensors and Bioelectronics, vol. 25, no. 9, pp. 2167-2171, 2010.

[10] S. L. Chen, H. Q. Hou, F. Harnisch et al., "Electrospun and solution blown three-dimensional carbon fiber nonwovens for application as electrodes in microbial fuel cells," Energy \& Environmental Science, vol. 4, no. 4, pp. 1417-1421, 2011.

[11] S. Chen, G. He, X. Hu et al., "A three-dimensionally ordered macroporous carbon derived from a natural resource as anode for microbial bioelectrochemical systems," ChemSusChem, vol. 5, no. 6, pp. 1059-1063, 2012.

[12] S. Chen, G. He, Q. Liu et al., "Layered corrugated electrode macrostructures boost microbial bioelectrocatalysis," Energy \& Environmental Science, vol. 5, no. 12, pp. 9769-9772, 2012.

[13] K. Scott, G. A. Rimbu, K. P. Katuri, K. K. Prasad, and I. M. Head, "Application of modified carbon anodes in microbial fuel cells," Process Safety and Environmental Protection, vol. 85, no. 5, pp. 481-488, 2007.

[14] D. Q. Jiang and B. K. Li, "Novel electrode materials to enhance the bacterial adhesion and increase the power generation in microbial fuel cells (MFCs)," Water Science \& Technology, vol. 59, no. 3, pp. 557-563, 2009.

[15] Y. Zhao, K. Watanabe, R. Nakamura et al., "Three-dimensional conductive Nanowire networks for maximizing anode performance in microbial fuel cells," Chemistry-A European Journal, vol. 16, no. 17, pp. 4982-4985, 2010.

[16] H. Y. Tsai, C. C. Wu, C. Y. Lee, and E. P. Shih, "Microbial fuel cell performance of multiwall carbon nanotubes on carbon cloth as electrodes," Journal of Power Sources, vol. 194, no. 1, pp. 199-205, 2009.

[17] Y. Zhang, G. Mo, X. Li et al., "A graphene modified anode to improve the performance of microbial fuel cells," Journal of Power Sources, vol. 196, no. 13, pp. 5402-5407, 2011.
[18] N. Thepsuparungsikul, N. Phonthamachai, and H. Ng, "Multiwalled carbon nanotubes as electrode material for microbial fuel cells," Water Science \& Technology, vol. 65, no. 7, pp. 12081214, 2012.

[19] X. Xie, M. Ye, L. Hu et al., "Carbon nanotube-coated macroporous sponge for microbial fuel cell electrodes," Energy \& Environmental Science, vol. 5, no. 1, pp. 5265-5270, 2012.

[20] X. Xie, L. Hu, M. Pasta et al., "Three-dimensional carbon nanotube-textile anode for high-performance microbial fuel cells," Nano Letters, vol. 11, no. 1, p. 291, 2011.

[21] D. Pant, G. Van Bogaert, L. Diels, and K. Vanbroekhoven, "A review of the substrates used in microbial fuel cells (MFCs) for sustainable energy production," Bioresource Technology, vol. 101, no. 6, pp. 1533-1543, 2010.

[22] Y. Zhao, K. Watanabe, and K. Hashimoto, "Hierarchical micro/nano structures of carbon composites as anodes for microbial fuel cells," Physical Chemistry Chemical Physics, vol. 13, no. 33, pp. 15016-15021, 2011. 


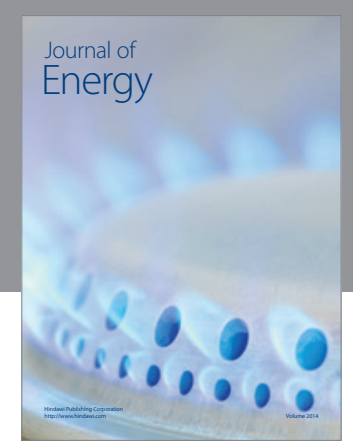

Journal of

Industrial Engineering
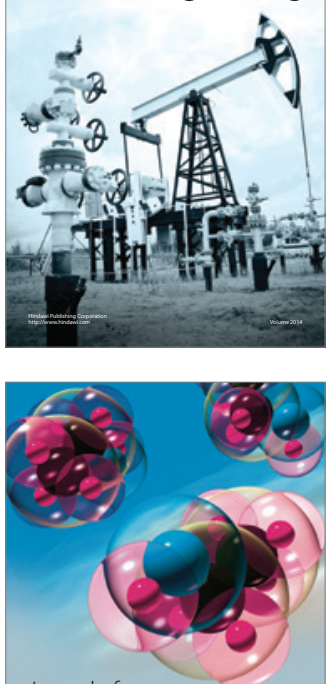

Fuels
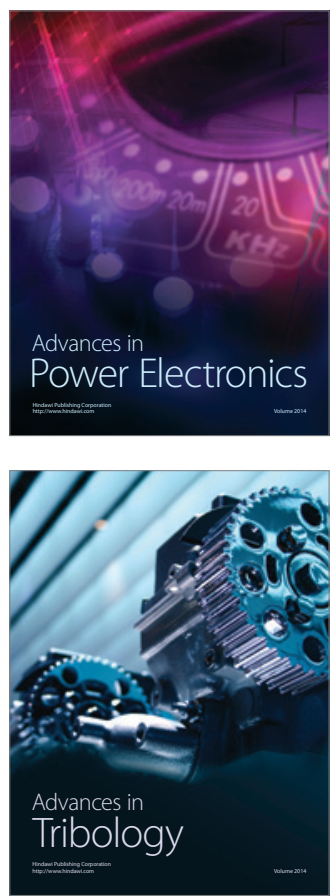

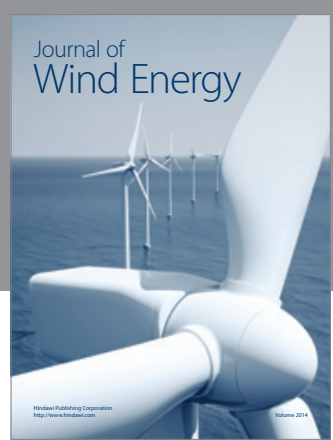

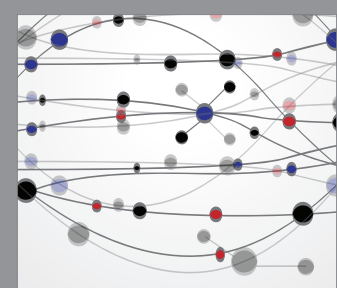

The Scientific World Journal

Submit your manuscripts at http://www.hindawi.com

Journal of

Structures
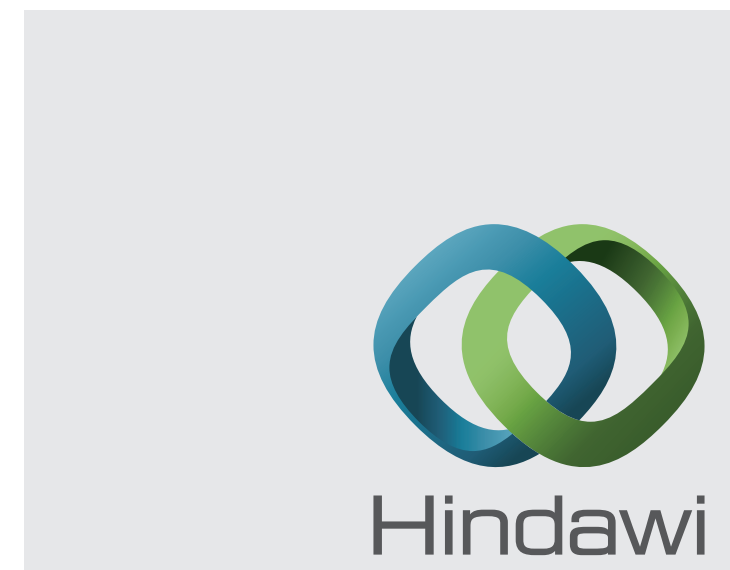

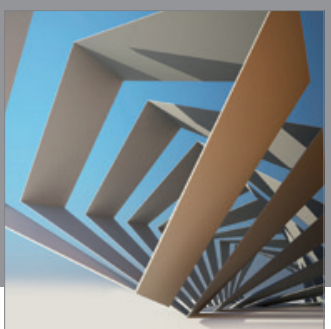

Rotating

Machinery
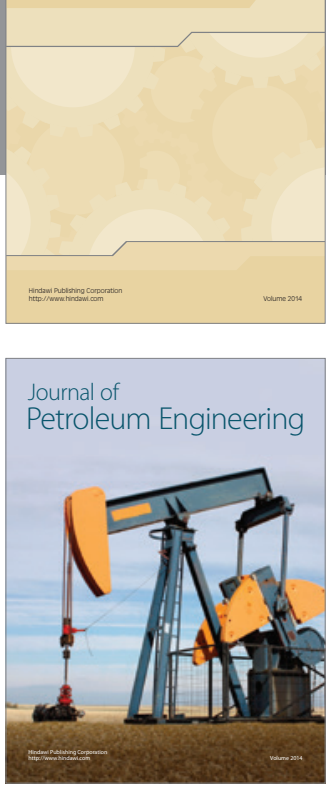

Journal of

Solar Energy
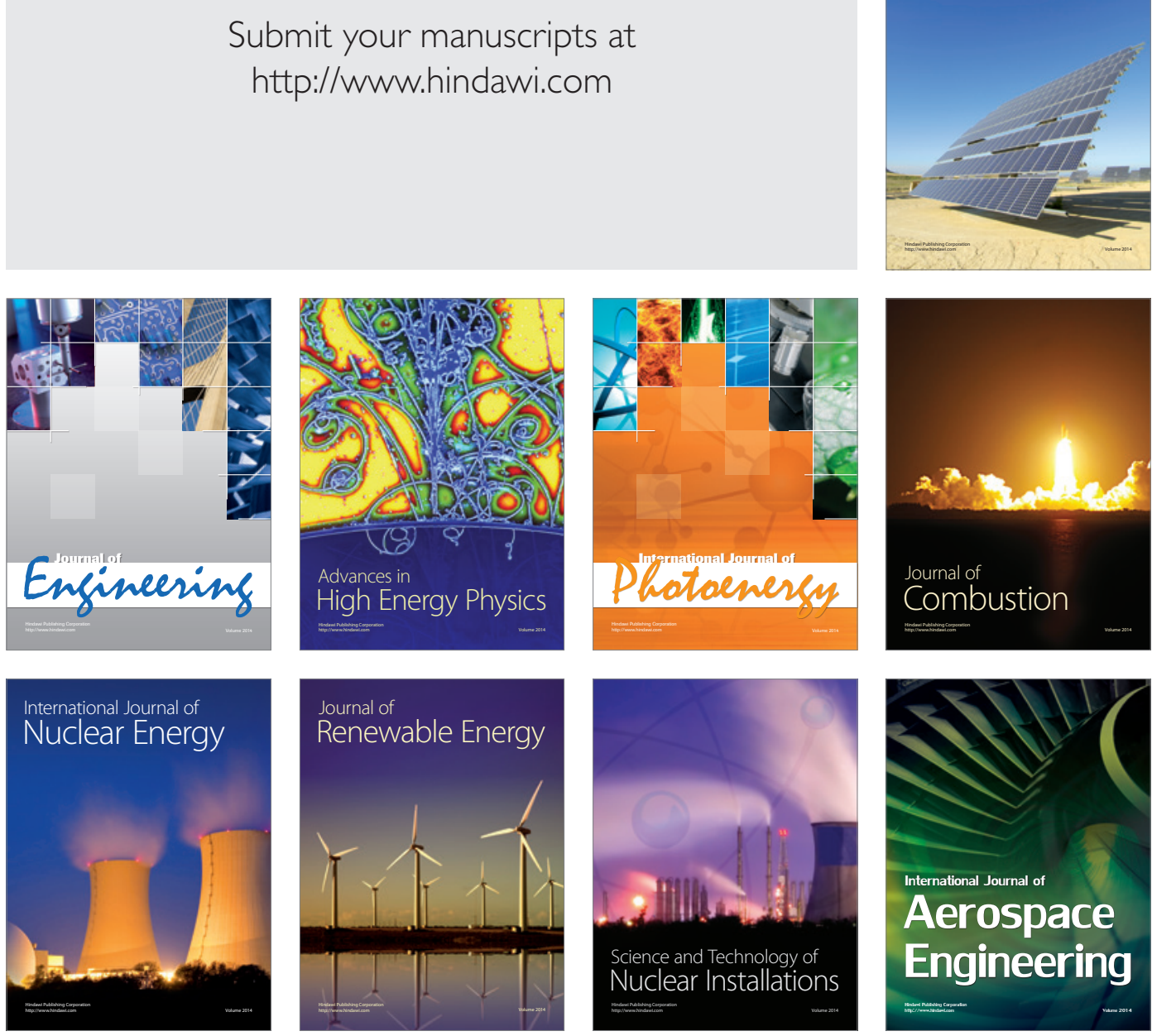